\title{
Volatile compounds from young peach shoots attract males of oriental fruit moth in the field
}

\section{$\operatorname{AUTHOR}(\mathrm{S}):$}

Il'ichev, Alex L.; Kugimiya, Soichi; Williams, David G.; Takabayashi, Junji

\section{CITATION:}

Il'ichev, Alex L....[et al]. Volatile compounds from young peach shoots attract males of oriental fruit moth in the field. Journal of Plant Interactions 2009, 4(4): 289-294

\section{ISSUE DATE:}

2009-12

URL:

http://hdl.handle.net/2433/88049

\section{RIGHT:}

c 2009 Taylor \& Francis. 許諾条件により本文は2011-01-01に公開.; この 論文は出版社版でありません。引用の際には出版社版をご確認ご利用 ください。; This is not the published version. Please cite only the published version. 
A. Il'ichev et al.

Journal of Plant Interactions

\title{
ORIGINAL ARTICLE
}

\section{Volatile Compounds from Young Peach Shoots attract Males of}

\section{Oriental Fruit Moth in the Field}

\author{
A.L. Il'ichev ${ }^{\mathrm{a}}$, S. Kugimiya ${ }^{\mathrm{b}}$, D.G. Williams ${ }^{\mathrm{a}}$ and J. Takabayashi ${ }^{\mathrm{c}^{*}}$ \\ ${ }^{a}$ Department of Primary Industries Victoria, Biosciences Research Division, Tatura \\ Centre, Private Bag 1, Tatura, Victoria 3616, Australia; \\ ${ }^{b}$ National Institute for Agro-Environmental Sciences, Kannodai 3-1-3, Tsukuba, 305- \\ 8604, Japan; \\ ${ }^{c}$ Center for Ecological Research, Kyoto University 2-509-3, Hirano, Otsu, 520-2113, \\ Japan.
}

Running head: Volatiles that attract oriental fruit moth males

A. L. and S. K. contributed equally to this work.

* Corresponding author. Email: junji@ecology.kyoto-u.ac.jp 
Oriental fruit moth (OFM) is one of the most important pests of commercial fruit orchards world-wide. Newly planted peach trees in particular, can be very attractive for mated OFM females for oviposition. Samples of airborne host plant volatiles from intact young peach shoot tips and old leaves of the same potted plants were collected and analysed with gas chromatograph-mass spectrometer. Chemicals present in young shoot tips, but not in old leaves, were used for field trials. Moth capture by traps with the synthetic chemicals was compared to that of the standard terpinyl acetate (TA) food trap. The TA food trap caught OFM males and mated females, but tested synthetic chemicals trapped only OFM males. We observed that the mixture of (Z)-3-hexenyl acetate: $(Z)$ - $\beta$-ocimene: $(E)$ - $\beta$-farnesene in proportion 1:2:2 attracted OFM males. Further, $1 \mathrm{mg}$ of $(Z)$ - $\beta$-ocimene, and that of $(E)-\beta$-farnesene also attracted OFM males.

Keywords: oriental fruit moth; Grapholita molesta; host plant volatile; field test; peach shoot tip. 


\section{Introduction}

Oriental fruit moth Grapholita molesta Busck (Lepidoptera: Tortricidae) (OFM) is one of the most important pests of commercial stone and pome fruit orchards. OFM originated from stone fruit in north-west China, but is now widely spread throughout the world including major stone fruit growing areas of Europe, Asia, America, Africa, Australia and New Zealand (Chapman and Lienk 1971). Stone fruit, and middle-late season varieties of peach and nectarine trees in particular, are considered to be the primary OFM host plants (Rothschild and Vickers 1991). In Australia, OFM severely damage not only peaches and nectarines, but also pears, apples, apricots and plums (Rothschild and Vickers 1991).

To control OFM in the field, it is important to monitor the population of OFM. Fermenting sugar baits have been used for a long time to attract Lepidoptera. Yetter and Steiner (1931) found that combination of terpinyl acetate (TA) with fermenting brown sugar solution dramatically increased attraction of OFM. However, TA food traps are not specific to OFM, attract large numbers of other insects and are very difficult to maintain because of rapid liquid evaporation in hot weather (Rothschild et al. 1984).

Identification of the OFM female sex pheromone structure (Roelofs et al. 1969; Carde et al. 1979) made new management options possible for this pest. Sex pheromone mediated mating disruption (MD) based on the release of large amounts of synthetic sex pheromone restricts the ability of males to locate virgin females (Rothschild 1975). MD, particularly when applied on an area-wide scale, was demonstrated to be an effective alternative to the use of broad-spectrum organophosphate insecticides for OFM control in Australia (Brown and Il'ichev 2000; Il'ichev et al. 2002). In addition, synthetic female sex pheromones have been used for 
specific monitoring of OFM males in orchards (Phillips 1973; Rothschild et al. 1984). However, this monitoring cannot be used in MD treated fields with the same pheromone. Thus, it is important to establish a novel monitoring method that can be used in MD treated fields.

Natale et al. (2003) reported that excised peach shoots were attractive to mated OFM females, and identified mixtures of (Z)-3-hexenyl acetate, $(Z)$-3-hexenol and benzaldehyde as OFM female attractants from the excised plants under laboratory conditions. They also reported that the major component of apple fruit volatiles, butyl hexanoate, was also attractive for mated OFM females (Natale et al. 2004). We also found that newly planted peach trees are especially attractive to mated OFM females for oviposition. Young shoot tips of peaches suffer most damage by OFM larvae (Il'ichev et al. 2003). In this study, we conducted headspace analysis of volatiles from intact young shoot tips of potted peach plants to identify possible candidates for OFM attractants. We then conducted field bioassays of compounds that were found quantitatively specific in the headspace of young shoot tips, with a major compound that was always found in the headspaces of both old leaves and young shoot tips. The field study reported here was part of a larger research project and the experimental design incorporated a number of test chemicals from other sources in addition to those identified and reported here from peach shoots.

\section{Materials and Methods}

\section{Collection of airborne host plant volatiles from intact young peach shoots}

Collection of airborne host plant volatiles was performed passively from the headspace of young peach shoots by stir bar sorptive extraction (SBSE) (Baltussen et al. 1999) 
using a magnetic stir bar coated with polydimethylsiloxane (PDMS) (“Gerstel Twister $^{\circledR}$ ” from Gerstel GmbH \& Co. KG; 0.5 mm film thickness and 10 mm length).

The collection of airborne volatiles was performed from the headspace of intact young peach shoot tips from 1 year-old potted peach plants (variety Tatura 204). Volatile collection was conducted in a fume cabinet in the laboratory natural light conditions with room temperature of about $24-25 C^{0}$ from 2 p.m. till 8 p.m. This method permitted to avoid collection of any volatiles produced from damage caused by cutting young shoot tips off twigs. Two cm of the young growing shoot tip was covered from the top by a small glass vial $(50 \mathrm{~mL})$ and the hole in the vial was sealed by aluminium foil placed around the twig. Individual stir bar was placed for 6 hours of volatile collection inside the glass vial, fixed carefully without touching anything other than the vial, using magnetic rods attached to the glass from outside the vial. Preliminary analysis revealed that 6 hours was the best time for sampling the plant volatiles, since the volatiles absorbed on PDMS reach equilibrium and after that they were desorbed. The airborne host plant volatiles were also collected from old peach leaves of the same potted plant by the same method to compare and to screen chemicals specific to newly grown shoot tips. The volatile collection was replicated using eight potted plants. A couple of stir bars were also placed individually inside empty glass vials to exclude background chemicals that could be detected. After collection of volatiles, each stir bar was recovered carefully and packed into another screw-cap glass vial $(1 \mathrm{~mL})$ for protection, which was placed into a deep freezer until the following chemical analysis was carried out.

\section{Chemical analysis}


Airborne host plant volatiles collected by stir bars were analysed by gas chromatography-mass spectrometry (GC-MS; GC: Agilent Technologies 6890 with an HP-5MS capillary column: $30 \mathrm{~m}$ long, $0.25 \mathrm{~mm}$ I.D. and $0.25 \mu \mathrm{m}$ file thickness, MS: Agilent Technologies 5973N mass selective detector), equipped with thermo-desorption system (TDS), cooled injection and cold trap (Gerstel GmbH \& Co. KG). GC-oven temperature was programmed to rise from $40^{\circ} \mathrm{C}\left(9 \mathrm{~min}\right.$. hold) to $280^{\circ} \mathrm{C}$ at $10^{\circ} \mathrm{C} / \mathrm{min}$. Compounds were tentatively identified by Wiley database, and then their mass-spectra and retention times were further checked with those of authentic compounds. Stereochemistries of some detected chiral compounds were not determined by further analysis. All authentic compounds were commercially available except for DMNT, which was synthesized only in small quantity in Takabayashi's laboratory in the Center for Ecological Research at Kyoto University, Japan.

\section{Field study and experimental design}

Six replicated field trials to test the response of OFM adults to a number of chemicals, individually and in mixtures, were conducted in a 20 hectare block of 5 year old Packham's Triumph pears within a large commercial orchard (about 20 hectares with approximately 8,000 pear trees) with a history of OFM infestation located at Ardmona, in the Greater Shepparton fruit production area of northern Victoria, Australia. The results of the field study shown here were extracted from the field studies using a large number of compounds.

Three trials were conducted in 2004-05 that tested a total of 15 chemicals including TA as control. Each individual trial in 2004-05 had seven chemicals plus TA as a control. The seven chemicals varied from trial to trial. The other three trials, conducted in 2005-06, tested a total of 31 chemicals including TA as control. Each 
individual trial had 14 chemicals plus TA as a control. The 14 chemicals varied from trial to trial. The focus of each trial was on comparing performance of each individual chemical with that of the control. Each trial was laid out in a randomised complete block design with four (during 2004-05) and three (during 2005-06) replications. The traps were grouped into 3-4 nearly homogeneous blocks to achieve higher precision and random assignment of chemicals to traps within each block ensured unbiased estimation of relative performance. Traps were equally spaced along a tree row within each block. Moth capture by traps with synthetic mixtures or individual chemicals was compared to that of the standard TA food trap (terpinyl acetate and fermenting brown sugar solution). The numbers of traps were 4 and 3 for each chemical treatment of Trial 1 - 3, and Trial 4 - 6, respectively.

The entire pear block was treated with a conventional insecticide spray program against codling moth, without any specific treatment against OFM. Whenever the pear orchard was treated for codling moth control, all plots were sprayed with the same insecticides (parathion-methyl and/or azinphos-methyl) applied about 7 times during the season.

\section{Traps and dispensers for field trials}

Standard Efecto-fly traps ${ }^{\circledR}$ (Avond Pty. Ltd., Narrogin, Western Australia) were used for testing chemicals and as food traps for OFM monitoring. Big red halo butyl rubber septa dispensers impregnated with tested chemicals (1 mg of a.i. in hexane solution per septa for individual chemicals and different doses for mixtures) were placed individually under the top of Effecto-fly traps for trials.

Efecto-fly traps were also used as terpinyl acetate (TA) food traps. Each TA food trap contained approximately 1 litre of $100 \mathrm{~g} / \mathrm{L}$ dark brown sugar solution with 12 
drops of terpinyl acetate solution $(48.5 \mathrm{~mL}$ of terpinyl acetate with $1.5 \mathrm{~mL}$ of non-ionic wetting agent and $50 \mathrm{~mL}$ of warm water). These TA food traps are not totally specific to OFM, but are commonly used to indicate the level of OFM population by catching males and females in fruit orchards treated with and without mating disruption.

\section{Trap placement and monitoring}

Each Effecto-fly trap in the experiment was placed at a distance of ca. $36 \mathrm{~m}$ away from the nearest trap within and across replications to minimise interference between traps. All traps were placed at a height of 1.5-2.0 $\mathrm{m}$ in the tree canopy. The sugar and terpinyl acetate solutions in the food traps were changed weekly after the trapped moths had been removed and identified. The traps with tested chemicals were also monitored weekly for OFM numbers. Trapping normally began at the end of August or beginning of September when the first OFM flight had started in spring in Victoria and continued for 6-8 weeks during each OFM flight. The moths caught in traps were weekly collected into vials with $75 \%$ ethanol and delivered to the laboratory for identification of OFM sex and female mating status. Sex identification was performed by examining genitalia under the dissecting microscope. For identification of female mating status, the abdomen of OFM females was dissected and bursa copulatrix inspected for presence of spermatophores.

\section{Statistical analysis}

Significant differences in relative intensities of each volatile compound detected by GCMS were analyzed by Mann-Whitney U-test between intact old leaves and young shoot tips. The cumulative number of OFM males caught per trap during the first 4 weeks of every trial was used for statistical analyses. For each trial, the data X on total OFM male 
catch across the four dates were analysed using analysis of variance (ANOVA) for a randomised complete block design. Chemicals that performed better than or equal to the control (TA food traps) were identified based on the unrestricted least significant difference (LSD) at 5\% level of significance. The analysis was carried out on a natural logarithmic scale $[\mathrm{Ln}(\mathrm{X}+1)]$ as this more reasonably satisfied the ANOVA assumptions of normality and constancy of variance. All computations were carried out in GenStat 8 statistical computing software. Results have been presented only for those chemicals that, in each trial, performed better than or equal to the control (TA food traps).

\section{Results and Discussion}

Seven compounds were detected from the headspace of intact peach old leaves and young shoot tips: $\alpha$-pinene, $\beta$-pinene, $(Z)$-3-hexenyl acetate, limonene, $(E)$ - $\beta$-ocimene, (E)-4,8-dimethyl-1,3,7-nonatriene (DMNT) and (E)- $\beta$-farnesene (Figure 1). Among them, the amounts of $(E)$ - $\beta$-ocimene, $(E)$-4,8-dimethyl-1,3,7-nonatriene (DMNT) and (E)- $\beta$-farnesene in the headspace of young shoot tips were significantly higher than those in old leaves. We hypothesized that those compounds were the candidates that attract OFM females to young shoot tips for oviposition. Natale et al. (2003) reported that (Z)-3-hexenyl acetate, (Z)-3-hexenol and benzaldehyde were detected from dissected peach shoots and that the mixture of the three compounds attracted OFM females under laboratory conditions. Initially in our study, we also carried out analysis of volatiles from dissected plants, which revealed that the three compounds and many other compounds reported by Natale et al. (2003) were released in substantial amounts from dissected young shoot tips as well as dissected old leaves (data not shown). They also demonstrated that the major component of apple fruit volatiles, butyl hexanoate, 
was attractive for only mated, but not virgin OFM females (Natale et al. 2004). Butyl hexanoate was not found in the headspace of intact young peach shoot tips in our study.

(Z)-3-Hexenyl acetate was a major compound found in both young shoot tips and old leaves. Thus, we used it in combination with the other two compounds specifically found in young shoot tips, as the mixtures of (Z)-3-hexenyl acetate: $(E)-\beta$ ocimene: $(E)$ - $\beta$-farnesene in 1:2:2 proportion and different doses (100 mg, $1 \mathrm{mg}, 100 \mu \mathrm{g}$ and $10 \mu \mathrm{g}$ ) for field trials. DMNT was identified with its authentic compound synthesized but was not tested in the field, because it was not available in quantity adequate for the tests.

Results presented in tables 1 and 2 refer only to those chemicals in the experiment that we identified from peach shoots. In the field tests, all tested mixtures of all concentrations caught only OFM males in the traps (Table 1). In contrast, both females and males were caught in TA food traps. After sex identification, only the number of males caught in TA food traps (control) was used for analysis to be compared with the tested chemicals, and found that the attractiveness of the mixtures in all concentrations was not significantly different from that of the control (Trial 1 and Trial 2). The highest OFM catch in TA food traps (control) was recorded during the flight of the first generation (trial 1 and 4) during both seasons (Tables 1, 2). The OFM numbers recorded in TA food traps during the second generation flight (trial 2 and 5) were similar during both seasons, but substantially lower than in the first flight. All tested mixtures of all concentrations during the first OFM flight (Trial 1, Table 1) demonstrated similar OFM catches, which were not significantly different from the control. The best performer in the first season during trials 1 and 2 was the $100 \mu \mathrm{g}$ mixture of (Z)-3-hexenyl acetate: (Z)- $\beta$-ocimene: (E)- $\beta$-farnesene in proportion 1:2:2 but in trial 3 it performed significantly worse than the control. During our field trials we 
observed a strong attraction to the tested mixtures and distinctive mating type of behaviour (Baker and Carde 1979) demonstrated by OFM males that started from early afternoon (around 2-3 p.m.) and continued until sunset (around 7-8 p.m.).

Individual chemicals were tested in the second season (Table 2, Trial 4-6). The performance of $(E)$ - $\beta$-farnesene and $(Z)$ - $\beta$-ocimene was slightly (but not significantly) higher than the control during the first OFM flight, but during the third flight (trial 6) catches on (E)- $\beta$-farnesene was significantly higher than in the control.

Timing of sprays to control OFM is currently based on physiological time accumulated from capture of male moths in traps. This relies on an assumed relationship between emergence of male and female moths. Since it is the females that lay eggs, the ability to monitor mated OFM females rather than males could provide more precise information for calculation of larval hatch date and improve timing of control measures. Discovery that the pear-derived kairomone ethyl (E,Z)-2,4decadienoate was attractive for codling moth males and females (Light et al. 2001) encouraged research to identify a similar attractant for mated OFM females. Such attractants may originate from airborne host plant volatiles produced by young growing peach shoot tips, because shoot tips suffer most damage by OFM larvae during the whole growing season in Australian orchards. Although this study identified potentially effective attractants for OFM males under field conditions by focusing on volatiles from young peach shoot tips, we did not identify any attractants for OFM females. .

The ecological functions of the attractiveness of the tested compounds in this study remain to be answered. On the other hand it was known for codling moth that some host plant volatiles could synergize and enhance sexual attraction of males to a sex pheromone source (Yang et al. 2004). The behavioural response of OFM males to the tested chemicals clearly demonstrated courtship and copulatory behaviour usually 
performed towards females and/or sex pheromone sources. Further study is needed to clarify the ecological functions of the attractiveness of the tested compounds and to identify the host plant compounds that attract mated OFM females to oviposition sites in the field.

\section{Acknowledgements}

This research was funded by the Department of Primary Industries (DPI), Victoria and Horticulture Australia Ltd. and conducted under the project FR-04009 "Improved attractants for monitoring and mass trapping of oriental fruit moth and codling moth females in orchards", and in part by grants of priority area (S) by Junji Takabayashi from the Ministry of Education, Culture, Sports, Science and Technology of Japan, and by Global COE program A06 of Kyoto University. We thank the following people from DPI Tatura: Dr. Subhash Chandra for experimental design discussions and for statistical analysis, Mr. Neil Penfold for trap monitoring and assistance with data preparation for analysis. Also we thank Mr. Stephen Sexton (BioGlobal Ltd. Qld., Australia) for supplying some individual chemicals for field trials. 


\section{References}

Baker TC, Carde RT. 1979. Courtship behaviour of the oriental fruit moth (Grapholita molesta): Experimental analysis and consideration of the role of sexual selection in the evolution of courtship pheromones in the Lepidoptera. Ann Entomol Soc Am. 72:173188.

Baltussen E, Sandra P, David F, Cramers C. 1999. Stir bar sorptive extraction (SBSE), a novel extraction technique for aqueous samples: Theory and principles. J Microcolumn Separations 11:737-747.

Brown DJ, Il'ichev AL. 2000. The potential for the removal of organophosphate insecticides from stone-fruit production in the Goulburn Valley, Australia. Acta Hort. 525:85-91.

Carde AM, Baker TC, Carde RT. 1979. Identification of a four-component sex pheromone of the female oriental fruit moth, Grapholitha molesta Busck. (Lepidoptera: Tortricidae). J Chem Ecol. 5:423-427.

Chapman PJ, Lienk SE. 1971. Tortricid fauna of apple in New York (Lepidoptera: Tortricidae); including an account of apples' occurrence in the State, especially as a naturalized plant. Special Publication March 1971, New York State Agric. Exp. Station, Cornell University, Geneva.

GenStat. 2005. GenStat 8 for Windows. Release 8.1. VSN International Ltd. Oxford. UK.

Il'ichev AL, Gut LJ, Williams DG, Hossain MS, Jerie PH. 2002. Area-wide approach for improved control of oriental fruit moth Grapholita molesta (Busck) (Lepidoptera: Tortricidae) by mating disruption. Gen Appl Ent. 31:7-15.

Il'ichev AL, Williams DG, Drago A. 2003. Distribution of the oriental fruit moth Grapholita molesta Busck (Lep., Tortricidae) infestation on newly planted peaches before and during 2 years of mating disruption. J Appl Entomol. 127:348-353.

Light DM, Knight AL, Henrick CA, Rajapaska D, Lingren B, Dickens JC, Reynolds KM, Buttery RG, Merrill G, Roitman J, Campbell BC. 2001. A pear-derived kairomone with pheromonal potency that attracts male and female codling moth, Cydia pomonella (L.). Naturwissenschaften 88:333-338.

Natale D, Mattiacci L, Hern A, Pasqualini E, Dorn S. 2003. Response of female Cydia molesta (Lepidoptera: Tortricidae) to plant derived volatiles. Bull Entomol Res. 93:335342.

Natale D, Mattiacci L, Pasqualini E, Dorn S. 2004. Apple and peach fruit volatiles and the apple constituent butyl hexanoate attract female oriental fruit moth Cydia molesta, in laboratory. J Appl Ent. 128:22-27. 
Phillips JR. 1973. Monitoring for oriental fruit moth with synthetic sex pheromone. Environ Entomol. 2:1039-1042.

Roelofs WL, Comeau A, Selle R. 1969. Sex pheromone of oriental fruit moth. Nature. 224:723

Rothschild GHL. 1975. Control of oriental fruit moth (Cydia molesta (Busck) (Lepidoptera, Tortricidae) with synthetic female pheromone. Bull Entomol Res. 65:473490.

Rothschild GHL, Vickers RA, Morton R. 1984. Monitoring the oriental fruit moth, Cydia molesta (Busck) (Lepidoptera: Tortricidae), with pheromone traps and bait pails in peach orchards in south-eastern Australia. Protection Ecology. 6:115-136.

Rothschild GHL, Vickers RA. 1991. Biology, Ecology and Control of the Oriental Fruit Moth. In: World Crop Pests, Vol. 5, Tortricid pests: their biology, natural enemies and control. Ed. by Van der Geest, L.P.S.; Evenhuis, H.H., Amsterdam, Elsevier, 389-412.

Yetter WP, Steiner LF. 1931. A preliminary report on large-scale bait trapping of the oriental fruit moth in Indiana and Georgia. J Econ Entomol. 24:1181-1197.

Yang Z, Bengtsson M, Witzgall P. 2004. Host plant volatiles synergize response to sex pheromone in codling moth, Cydia pomonella. J Chem Ecol. 30:619-629. 


\section{Figure caption}

Figure 1. Host plant volatile compounds detected by GC-MS analysis from intact old leaves and young shoot tips of the same potted peach tree (mean \pm SEM, relative intensity by total ion chromatogram). Asterisks mean significant differences in relative intensities of each compound detected from between old leaves and young shoot tips (*: $P<0.05$; ***: $P<0.001$ by Mann-Whitney $U$-test, $n=8$ ). 1: $\alpha$-Pinene; 2: $\beta$-Pinene; 3: (Z)-3-Hexenyl acetate; 4: Limonene; 5: (E)- $\beta$-Ocimene; 6: (E)-4,8-Dimethyl-1,3,7nonatriene (DMNT); 7: (E)- $\beta$-Farnesene 


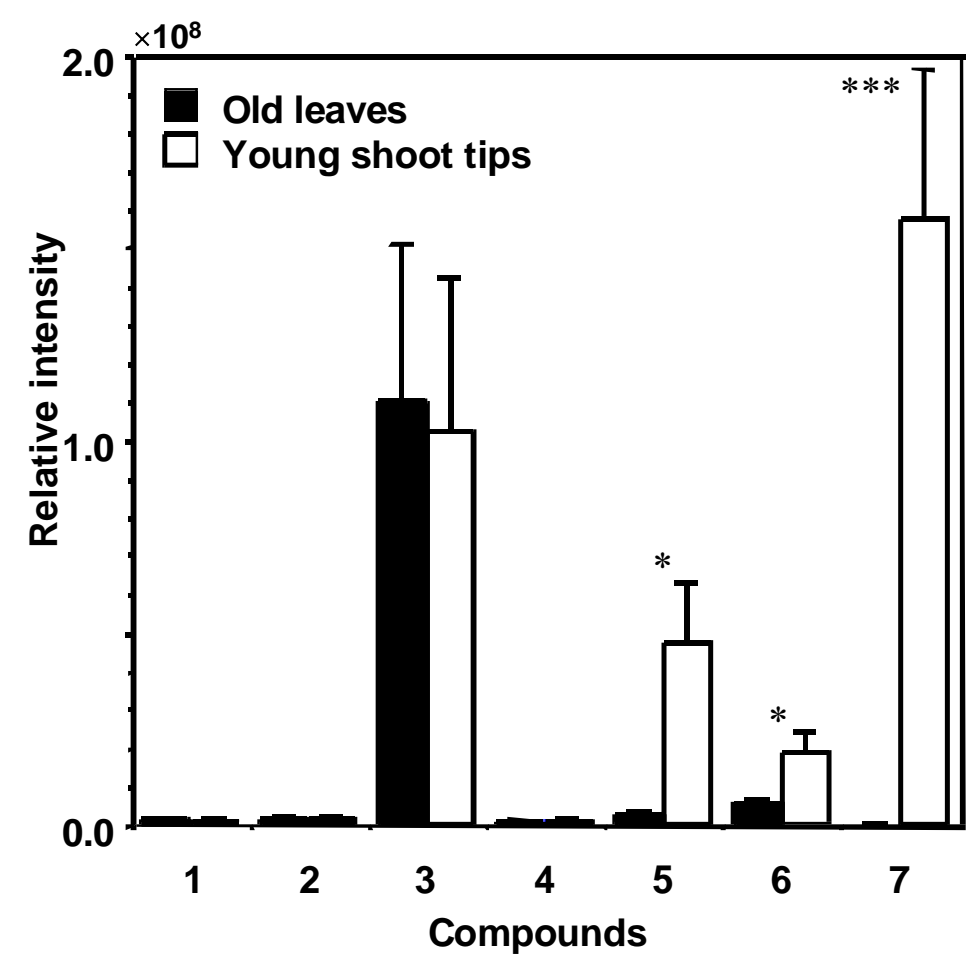

Figure 1 
Table 1. Average total catch of OFM males for chemicals during one or more trials in the 2004-05 season. Figures presented are means and SE of the raw data from 4 replications of each chemical and the $\operatorname{Ln}(\mathrm{X}+1)$ transformed means (Ln). F-Probability and LSD are derived from analysis of $\operatorname{Ln}(\mathrm{X}+1)$ transformed data from the entire experimental dataset for each trial, not just those chemicals presented below. Figures followed by ! are significantly worse than the control. Significant F-Probabilities without annotated figures in the relevant column indicate that other chemicals in the dataset were significantly different to the control. These were not reported because they were not derived from peach shoot tip volatiles.

\begin{tabular}{|c|c|c|c|c|c|c|}
\hline \multirow{2}{*}{$\begin{array}{l}\text { Chemical names, mixtures, and } \\
\text { dose tested (a.i. per septa) }\end{array}$} & \multicolumn{2}{|c|}{ Trial 1} & \multicolumn{2}{|c|}{ Trial 2} & \multicolumn{2}{|c|}{ Trial 3} \\
\hline & $\begin{array}{l}\text { Mean } \\
\text { (SE) }\end{array}$ & Ln & $\begin{array}{l}\text { Mean } \\
(\mathrm{SE})\end{array}$ & Ln & $\begin{array}{l}\text { Mean } \\
\text { (SE) }\end{array}$ & Ln \\
\hline $\begin{array}{l}\text { Control - TA food trap (terpinyl } \\
\text { acetate and fermenting brown sugar } \\
\text { solution) }\end{array}$ & $\begin{array}{c}159.8 \\
(42.02)\end{array}$ & 4.97 & $\begin{array}{c}49.25 \\
(11.947)\end{array}$ & 3.84 & $\begin{array}{c}16 \\
(6.364)\end{array}$ & 2.67 \\
\hline $\begin{array}{l}\text { (Z)-3-hexenyl } \\
\text { acetate:(Z)- } \beta \text {-ocimene:(E)- } \beta \text {-farnesene } \\
1: 2: 2 ; \quad 100 \mathrm{mg}\end{array}$ & $\begin{array}{c}67.8 \\
(25.12)\end{array}$ & 4.06 & & & & \\
\hline $\begin{array}{l}\text { (Z)-3-hexenyl } \\
\text { acetate:(Z)- } \beta \text {-ocimene:(E)- } \beta \text {-farnesene } \\
1: 2: 2 ; \quad 1 \mathrm{mg}\end{array}$ & $\begin{array}{c}61.8 \\
(15.4)\end{array}$ & 4.05 & & & & \\
\hline $\begin{array}{l}\text { (Z)-3-hexenyl } \\
\text { acetate:(Z)- } \beta \text {-ocimene:(E)- } \beta \text {-farnesene } \\
1: 2: 2 ; \quad 100 \mu \mathrm{g}\end{array}$ & $\begin{array}{l}130.5 \\
(56.4)\end{array}$ & 4.27 & $\begin{array}{c}18 \\
(5.339)\end{array}$ & 2.81 & $\begin{array}{c}1.25 \\
(1.25)\end{array}$ & $0.45 !$ \\
\hline $\begin{array}{l}\text { (Z)-3-hexenyl } \\
\text { acetate:(Z)- } \beta \text {-ocimene:(E)- } \beta \text {-farnesene } \\
1: 2: 2 ; \quad 10 \mu \mathrm{g}\end{array}$ & $\begin{array}{c}86.8 \\
(34.28)\end{array}$ & 4.15 & & & & \\
\hline $\begin{array}{l}\text { F-Prob } \\
\text { LSD (5\%) }\end{array}$ & & $\begin{array}{l}0.016 \\
1.464\end{array}$ & & $\begin{array}{l}<0.001 \\
1.045\end{array}$ & & $\begin{array}{l}0.005 \\
1.202 \\
\end{array}$ \\
\hline
\end{tabular}


Table 2. Average total catch of OFM males for chemicals during one or more trials in the 2005-06 season. Figures presented are the means and SE of the raw data from 3 replications of each chemical and the $\operatorname{Ln}(\mathrm{X}+1)$ transformed means $(\mathrm{Ln})$. F-Probability and LSD are derived from analysis of $\operatorname{Ln}(\mathrm{X}+1)$ transformed data from the entire experimental dataset for each trial, not just those chemicals presented below. Figures followed by * are significantly better than the control. Figures followed by ! are significantly worse than the control. Significant F-Probabilities without annotated figures in the relevant column indicate that other chemicals in the dataset were significantly different to the control. These were not reported because they were not derived from peach shoot tip volatiles.

\begin{tabular}{|c|c|c|c|c|c|c|}
\hline \multirow{2}{*}{$\begin{array}{l}\text { Chemical names, mixtures, } \\
\text { and dose tested (a.i. per septa) }\end{array}$} & \multicolumn{2}{|c|}{ Trial 4} & \multicolumn{2}{|c|}{ Trial 5} & \multicolumn{2}{|c|}{ Trial 6} \\
\hline & $\begin{array}{l}\text { Mean } \\
\text { (SE) }\end{array}$ & Ln & $\begin{array}{l}\text { Mean } \\
\text { (SE) }\end{array}$ & Ln & $\begin{array}{l}\text { Mean } \\
\text { (SE) }\end{array}$ & Ln \\
\hline $\begin{array}{l}\text { Control - TA food trap (terpinyl } \\
\text { acetate and fermenting brown } \\
\text { sugar solution) }\end{array}$ & $\begin{array}{c}462.3 \\
(109.7)\end{array}$ & 6.08 & $\begin{array}{c}51 \\
(15.177)\end{array}$ & 3.83 & $\begin{array}{c}39 \\
(24.58)\end{array}$ & 3.31 \\
\hline (E)- $\beta$-farnesene; $1 \mathrm{mg}$ & $\begin{array}{c}526.7 \\
(168.6)\end{array}$ & 6.15 & $\begin{array}{c}12.33 \\
(4.055)\end{array}$ & 2.48 & $\begin{array}{c}108 \\
(23.12)\end{array}$ & $4.64^{*}$ \\
\hline (Z)- $\beta$-ocimene; $1 \mathrm{mg}$ & $\begin{array}{l}594.3 \\
(281.2)\end{array}$ & 6.17 & $\begin{array}{c}11.67 \\
(8.413)\end{array}$ & $1.82 !$ & $\begin{array}{c}48.33 \\
(35.93)\end{array}$ & 3.29 \\
\hline $\begin{array}{l}\text { F-Prob } \\
\text { LSD (5\%) }\end{array}$ & & $\begin{array}{l}0.222 \\
1.492\end{array}$ & & $\begin{array}{l}0.024 \\
1.733\end{array}$ & & $\begin{array}{l}<0.001 \\
1.252\end{array}$ \\
\hline
\end{tabular}

